certainly follow that the hydrochloride from much of the dextro American oil must show a negative rotation. But this is not in agreement with the facts.

Pesci appears to be in error, with others, in giving the melting-point of the hydrochloride as $125^{\circ}$. A careful determination of three preparations from rather large amounts of purified and fractionated oil gives me $131^{\circ}$ as the true melting-point, and this agrees with the value given by Riban.'

My thanks are due Mr. Frank Wright for valuable help in preparing samples of the hydrochloride and in determination of the optical constants.

CHICAgo, April, isog.

[CONTRIBUTIONS FROM THE JOHN HARRISON LABORATORY OF CHEMISTRY, No. 39].

\title{
SEPARATIONS OF METALLIC SULPHIDES BY MEANS OF HYDROCHLORIC ACID GAS.
}

BY J. BIRD MOYER.

Received April 3, regg.

$A \begin{aligned} & \text { NUMBER of quantitative separations have been made in } \\ & \text { the last few years through the agency of the haloid acids }\end{aligned}$ in gas form. With a few exceptions the experiments made in this laboratory and elsewhere required the use of metallic oxides or the salts of oxygen acids. The analogy of sulphur to oxygen in its derivatives led to the conclusion that similar behavior might be expected from the metallic sulphides. Smith and Keeley ${ }^{\prime}$ found that arsenic sulphide, antimony sulphide, and stannic sulphide were completely volatilized in a stream of hydrochloric acid gas and that stannous sulphide, though not volatilized, was changed to stannous chloride. An attempt was made by them to effect a separation of stannic sulphide from stannous sulphide in this manner but it proved unsuccessful. Smith and Field ${ }^{2}$ separated arsenic sulphide from vanadium sulphide quantitatively by this method.

The acid sulphides being volatile in hydrochloric acid gas it was natural to suppose that they might be separated quantitatively from the more basic metallic sulphides. It was hardly

1 Wurtz's Dictionary, vol, V, 306 and 3 I 2.

2 This Journal, $18, \log 6$.

8 Ibid., 18, 105 I. 
expected that such a course, though possible, would be pursued in ordinary analytical chemistry, yet it was thought that an investigation of this field might prove interesting. The sulphides for this purpose were precipitated, carefully washed and dried; in some cases, however, to avoid the oxidation which is common in the drying of moist sulphides, they were made by igniting the oxide in a stream of hydrogen sulphide. The dry sulphides were placed in a porcelain boat, weighed and heated in a glass combustion tube, through which was passed a current of hydrochloric acid gas.

Separation of Lead from Arsenic. - The dry sulphide of lead, not proving volatile in hydrochloric acid gas, was mixed with dry arsenic sulphide and heated until all of the arsenic was eliminated. Usually the lead sulphide changed completely to chloride and was weighed as such. It was then taken up in hot water and evaporated down with sulphuric acid and weighed as sulphate with the following results:

$\begin{array}{ccccccc}\text { Expt. } & \begin{array}{c}\text { PbS } \\ \text { taken. }\end{array} & \begin{array}{c}\mathrm{As}_{2} \mathrm{~S}_{9} \\ \text { taken. }\end{array} & \begin{array}{c}\mathrm{PbCl}_{2} \\ \text { obtained. }\end{array} & \begin{array}{c}\mathrm{PbCl}_{2} \\ \text { calculated. }\end{array} & \begin{array}{c}\mathrm{PbsO}_{4} \\ \text { obtained. }\end{array} & \begin{array}{c}\mathrm{PbSO}_{4} \\ \text { calculated. }\end{array} \\ \text { I } \ldots \ldots & \ldots . I 174 & 0.1045 & 0.1350 & 0.1366 & \ldots \ldots & \ldots \\ \text { II } \ldots \ldots & 0.3230 & 0.1175 & 0.3763 & 0.3758 & 0.4105 & 0.4097 \\ \text { III } \ldots \ldots & 0.1406 & 0.1 I 00 & 0.1630 & 0.1636 & 0.1764 & 0.1783\end{array}$

In Experiment I the chloride dissolved in hot water leaving a small residue of lead sulphide, but no arsenic, which accounts for the low result.

Lead from Antimony. - The experiments with antimony did not yield results which were entirely satisfactory although this sulphide is known to be volatile. In these experiments it was found that the sulphide of antimony volatilized rapidly at first but more sluggishly toward the end, while the last traces were hard to remove. This fact makes it difficult to decide just when the separation is completed. The results obtained with antimony sulphide, prepared in the dry way, were no better. These figures were obtained:

$\begin{array}{ccccccc}\text { Expt. } & \begin{array}{c}\mathrm{PbS} \\ \text { taken. }\end{array} & \begin{array}{c}\mathrm{Sb}_{2} \mathrm{~S}_{3} \\ \text { taken. }\end{array} & \begin{array}{c}\mathrm{PbCl}_{2} \\ \text { obtained. }\end{array} & \begin{array}{c}\mathrm{PbCl}_{2} \\ \text { calculated. }\end{array} & \begin{array}{c}\mathrm{PbSO} \\ \text { obtained. }\end{array} & \begin{array}{c}\mathrm{PbSO}_{4} \\ \text { calculated. }\end{array} \\ \mathrm{I} \ldots \ldots & 0.1837 & 0.289 \mathrm{I} & \ldots \ldots & \ldots . & 0.2296 & 0.2230 \\ \mathrm{II} \ldots \ldots & 0.1294 & 0.1100 & 0.1513 & 0.1505 & 0.1648 & 0.1640\end{array}$

Lead from Bismuth.-Bismuth sulphide like the oxide volatilizes slowly in hydrochloric acid gas. The time required de- 
pends upon the amount taken. In the first experiment the bismuth sulphide changed in the cold and volatilized at a low temperature, while in the second experiment heat was applied for three or four hours.

$\begin{array}{ccccc}\text { Expt. } & \begin{array}{c}\mathrm{Pbs} \\ \text { taken. }\end{array} & \begin{array}{c}\mathrm{Bi}_{2} \mathrm{~S}_{3} \\ \text { taken, }\end{array} & \begin{array}{c}\mathrm{PbsO}_{4} \\ \text { obtained. }\end{array} & \begin{array}{c}\mathrm{PbSO}_{4} \\ \text { calculated. }\end{array} \\ \mathrm{I} \ldots \ldots \ldots \ldots \ldots & 0.1093 & 0.1 \mathrm{I}^{2} \mathrm{I} & 0.13^{89} & 0.1386 \\ \mathrm{II} \ldots \ldots \ldots \ldots \ldots \ldots & 0.674 \mathrm{I} & 0.2638 & 0.8525 & 0.855^{\circ}\end{array}$

There was no bismuth found with the lead after the reaction.

Cadmium from Arsenic.-Experiments with cadmium sulphide show that it does not volatilize except at a high temperature, consequently it is an easy matter to remove the arsenic from a mixture of their dry sulphides. The following results were obtained:

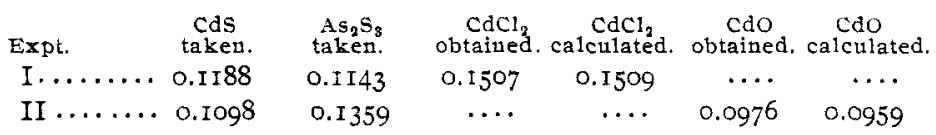

In Experiment II, the cadmium sulphide was not all changed to chloride. The residue was, therefore, made into a paste with hydrochloric acid and pure mercuric oxide, ignited and weighed as oxide. A third experiment was tried using cadmium arsenate which was heated in hydrogen sulphide gas and then in hydrochloric acid gas.

Gram.

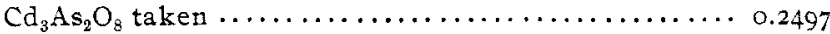

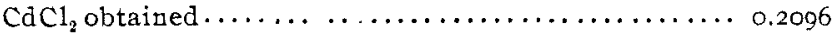

$\mathrm{CdCl}_{2}$ calculated $\ldots \ldots \ldots \ldots \ldots \ldots \ldots \ldots \ldots \ldots \ldots \ldots \ldots \ldots \ldots \ldots .2109$

The separation was complete in two hours at a temperature of I $70^{\circ} \mathrm{C}$.

Silver from Arsenic. - Silver arsenate was heated in a stream of hydrogen sulphide until it turned black. A temperature of about $190^{\circ} \mathrm{C}$. was required. Hydrochloric acid gas was then substituted for the hydrogen sulphide and the temperature increased from $200^{\circ}$ to $250^{\circ}$, when the mixture of silver and arsenic sulphides was visibly attacked. The mass melted, and the arsenic volatilized rapidly, leaving a white residue of silver chloride. Results :

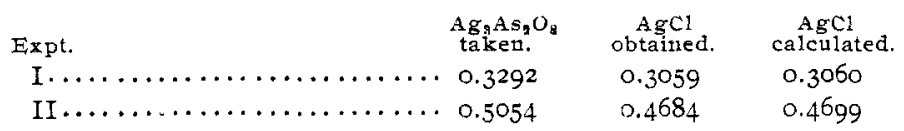


The result in Experiment $I$ is very close to the theoretical. In the second experiment the result is good but shows a slight loss from sublimation. A higher temperature was required in the latter case to start the reaction and a naked flame was applied for a few minutes, which occasioned a faint sublimate of silver chloride just above the boat. The arsenic was found to be completely eliminated.

The above results show that it is not impossible to separate sulphides as well as oxides by means of hydrochloric acid gas. The sulphides of arsenic, antimony, and bismuth may thus be separated from lead sulphide, and the sulphide of arsenic from the sulphides of cadmitum and silver. One more volatile sulphide, the sulphide of bismuth, should be included with those already mentioned. This might well be expected as the oxide volatilized in hydrochloric acid gas. This volatility of bismuth affords a method of purifying lead compounds which contain it, as its oxide or sulphide will be entirely removed by the use of hydrochloric acid gas. It is not unlikely that further separations depending upon the volatility of arsenic, antimony, tin, and bismuth sulphides may be made and the number of possible separations thus considerably increased.

The non-volatile sulphides were converted into chlorides with a variable degree of success. This in some cases depended upon the manner of their preparation. An interesting example of this was the behavior of antimony sulphide. A portion of the precipitated sulphide was heated in hydrogen sulphide to render it homogeneous, when it melted, and after cooling slowly in this gas, it crystallized nicely as stibnite. In this form it was volatilized with difficulty.

UNIVERSITY OF PENNSYLVANIA, March 29, 1899 .

\section{THE INCANDESCENT ELECTRIC LAMP AS A SOURCE OF HEAT IN ETHER EXTRACTION.}

By C. G. Hopkins.

Received March 20, 1899 .

\footnotetext{
$A^{S}$ a substitute for the electric heater recently described by A sammis ${ }^{1}$ the writer employs the ordinary incandescent lamp in extraction work. The arrangement of twenty complete 1 This JOORNAL, 21,42 (I899).
} 